\title{
RESEARCH
}

Open Access

\section{"Can do, don't do" are not the lazy ones: a longitudinal study on physical functioning in patients with COPD}

Noriane A. Sievi ${ }^{1} \mathbb{B}$, Thomas Brack ${ }^{2}$, Martin H. Brutsche ${ }^{3}$, Martin Frey ${ }^{4}$, Sarosh Irani ${ }^{5}$, Jörg D. Leuppi ${ }^{6}$, Robert Thurnheer ${ }^{7}$, Malcolm Kohler ${ }^{1,8}$ and Christian F. Clarenbach ${ }^{1 *}$

\begin{abstract}
Background and objective: Reduced physical capacity (PC) and physical activity (PA) are common in COPD patients and associated with poor outcome. However, they represent different aspects of physical functioning and interventions do not affect them in the same manner. To address this, a new PC-PA quadrant concept was recently generated to identify clinical characteristics of sub-groups of physical functioning. The objective of this study was to I) proof the new concept and to verify their differentiating clinical characteristics, II) evaluate the consistency of the concept over time, III) assess whether patients changed their quadrant affiliation over time, IV) and to test if changes in quadrant affiliations are associated with changes in clinical characteristics.
\end{abstract}

Methods: In a longitudinal, prospective, non-interventional cohort with mild to very severe COPD patients, PC and PA as well as respiratory variables, COPD-specific health status, comorbidities, survival, and exacerbations were yearly assessed.

Results: Data from 283 patients were analysed at baseline. Mean (min/max) follow-up time was $2.4(0.5 / 6.8)$ years. The PC-PA quadrants could be characterized as follows: I) "can't do, don't do": most severe and symptomatic, several comorbidities II) "can do, don't do": severe but less symptomatic, several comorbidities III) "can't do, do do": few patients, severe and symptomatic, less comorbidities IV) "can do, do do": mildest and less symptomatic, less comorbidities, lowest exacerbation frequency. Of the 172 patients with at least one follow-up, 58\% patients never changed their quadrant affiliation, while 17\% declined either PC, PA or both, 11\% improved their PC, PA or both, and $14 \%$ showed improvement and decline in PC, PA or both during study period. None of the clinical characteristics or their annual changes showed consistent significant and relevant differences between all individual sub-groups.

Conclusion: Our findings suggest that there are no clinical characteristics allowing to distinguish between the PCPA quadrants and the concept seems not able to illustrate disease process. However, the already low PA but preserved PC in the "can do, don't do" quadrant raises the question if regularly assessment of PA in clinical practice would be more sensitive to detect progressive deterioration of COPD compared to the commonly used PC.

Clinical trial registration: www.ClinicalTrials.gov, NCT01527773.

Keywords: COPD, Physical activity, Exercise capacity, Longitudinal analysis

\footnotetext{
* Correspondence: christian.clarenbach@usz.ch

${ }^{1}$ Pulmonary Division, University Hospital Zurich, Raemistrasse 100, 8091

Zurich, Switzerland

Full list of author information is available at the end of the article
}

(c) The Author(s). 2020 Open Access This article is distributed under the terms of the Creative Commons Attribution 4.0 International License (http://creativecommons.org/licenses/by/4.0/), which permits unrestricted use, distribution, and reproduction in any medium, provided you give appropriate credit to the original author(s) and the source, provide a link to the Creative Commons license, and indicate if changes were made. The Creative Commons Public Domain Dedication waiver (http://creativecommons.org/publicdomain/zero/1.0/) applies to the data made available in this article, unless otherwise stated. 


\section{Introduction}

Chronic obstructive pulmonary disease (COPD) is frequently accompanied by impaired physical capacity (PC) and reduced daily physical activity (PA), both arising in early disease stages [1]. Moreover, COPD patients are less physically active than patients with other chronic diseases, such as diabetes and rheumatoid arthritis [2]. Both, reduced ability to perform PA and PC, are known to be associated with a poor outcome (impaired health status, increased healthcare utilization) and are strong predictors for all-cause mortality in COPD [3, 4]. PC and PA represent two different aspects of physical functioning. While PC represents the ability to perform activity (a set of attributes), PA represents what people really do during their daily routine (a complex behaviour) [5]. A recent longitudinal assessment of the courses of PC and PA in COPD patients showed that PC remained stable despite a substantial annual decrease in PA [6]. This finding leads to our hypothesis, that the longitudinal decline in PA cannot be explained by a concomitant reduction in exercise tolerance. Furthermore, pulmonary rehabilitation shows a positive impact on PC [7] but incongruent findings on PA improvement [8], suggesting that an improvement in PC does not consistently lead to an increase in PA. Further interventions such as PA counselling or long-term oxygen therapy showed variable effects on PA enhancement [9], but studies comparing the effects of these interventions on $\mathrm{PC}$ and PA are missing. This implies that interventions may have to be individually tailored according to patients' impairments in $\mathrm{PC}$ or $\mathrm{PA}$, or both. According to this new approach, Koolen et al. [10] recently developed a PC-PA quadrant concept with PC ("can do") and PA ("do do") plotted against axes. This PC-PA quadrant concept identifies sub-groups of physical functioning and comparison of different clinical characteristics may provide an explanation for the discrepancies between PA and $\mathrm{PC}$ in individual COPD patients.

To address the request of the authors to proof their newly introduced PC-PA quadrant concept in another heterogeneous COPD cohort [10], we performed the analysis accordingly and verified their findings regarding differences in clinical characteristics in our cohort. Furthermore, additional characteristics were compared among the quadrants. Due to our longitudinal study design, we assessed I) the consistency of the concept over time, II) whether patients changed their quadrant affiliation over time, III) and if changes in quadrant affiliations are associated with changes in clinical characteristics.

\section{Methods}

\section{Subjects}

In the prospective, non-interventional cohort project "The Obstructive Pulmonary Disease Outcomes Cohort
Study (TOPDOCS)" patients with already diagnosed mild to very severe COPD from seven pulmonary outpatient clinics in Switzerland were included. Study period was from October 2010 to December 2017 and took place during outpatient visits or hospital stays. Patients were scheduled for initially three annual study visits (some patients extended their participation up to seven study visits). This analysis included data from 283 COPD patients out of the TOPDOCS cohort. Patients aged between 40 and 75 years at inclusion with confirmed COPD according to Global Initiative for Chronic Obstructive Lung Disease (GOLD)-guidelines [11] were assessed for eligibility. Patients were excluded if they suffered from mental or physical disability precluding informed consent or compliance with the protocol. In case of a COPD exacerbation, patients were included into the study or called up for follow-up visits with a delay of at least 6 weeks.

The study was conducted in accordance with the declaration of Helsinki and all subjects gave written informed consent to participate. The Ethics Committee of the Canton of Zurich approved the study (EK-ZH-NR: 1734 and 2011-0106) and the study is registered at www.ClinicalTrials.gov, NCT01527773.

\section{Measurements \\ Physical capacity}

The 6-min walking distance (6MWD) was annually assessed according to the American Thoracic Society (ATS) guidelines [12]. The 6-min walking test (6MWT) was performed on a $75 \mathrm{~m}$ indoor track, and patients were told to walk as far as possible within six minutes. Oxygen supplementation was allowed if required. At start and end of the test, peripheral oxygen saturation was measured by oximeter (PC-60C Fingertip Oximeter, Shanghai International Trading Corp. GmbH, Hamburg, Germany). Percentage of predicted values of 6MWD was calculated by reference equation of Enright et al. [13] The minimal important difference (MID) for 6MWD in COPD patients is estimated as $25 \mathrm{~m}$ [14].

\section{Physical activity}

The number of steps per day was measured by a validated, triaxial accelerometer of a multisensory activity monitor (SenseWear Pro ${ }^{\mathrm{Tm}}$; Bodymedia Inc., Pittsburgh, PA, USA) without a display (patient were blinded to the amount of steps per day) [15]. The monitor was worn on the upper left arm for 7 consecutive days once a year. The threshold for valid data from the armband was set at 4 days with a minimum of $22.5 \mathrm{~h} /$ day. Seasonality was considered in the analysis. A change of 600 to 1100 steps per day is supported to be the MID in COPD patients [16]. 


\section{PC-PA quadrant concept}

As described in the manuscript by Koolen and colleagues [10], the PC-PA quadrants were plotted as follows: "can't do, don't do" quadrant with low PC (6MWD $<70 \%$ pred.) and low PA (number of steps per day < 5000 steps); "can do, don't do" quadrant with preserved PC (6MWD $\geq 70 \%$ pred.) but low PA (number of steps per day < 5000 steps); "can't do, do do" quadrant with low PC $(6 \mathrm{MWD}<70 \%$ pred.) but preserved PA (number of steps per day $\geq 5000$ steps); "can do, do do" quadrant with preserved $\mathrm{PC}(6 \mathrm{MWD} \geq 70 \%$ pred.) and preserved PA (number of steps per day $\geq 5000$ steps).

To assess the longitudinal course of the PC-PA quadrant concept, patients were categorized into four "changing groups" according to their quadrant affiliations over time. COPD patients who never changed their PC-PA quadrant during study period were categorized as "remainer", "decliner" were patients who decreased their physical functioning (decline in 6MWD $<70 \%$ pred. and/or number of steps per day $<5000$ steps) at least once, "improver" increased their physical functioning over time (increase in 6MWD $\geq 70 \%$ pred. and/or number of steps per day $>5000$ steps) at least once, and "waverer" included patients who increased and decreased their physical functioning over time (increase and/or decrease in 6MWD and/or increase and/or decrease in steps per day) at least once.

\section{Respiratory variables}

Standard pulmonary functional testing was performed according to ATS/ERS guidelines $[17,18]$ to measure forced expiratory volume in one second $\left(\mathrm{FEV}_{1}\right)$, residual volume to total lung capacity (RV/TLC) ratio, and diffusing capacity of the lung for carbon monoxide (DLco). Only values after bronchodilation were reported. Disease severity was assessed by spirometric GOLD stages (stage 1-4) and COPD risk groups (risk score A-D) [19].

\section{Blood gas analysis}

Daytime arterial blood gas analysis was performed to assess partial pressure of oxygen $\left(\mathrm{PaO}_{2}\right)$, of carbon dioxide $\left(\mathrm{PaCO}_{2}\right)$ and oxygen saturation $\left(\mathrm{SaO}_{2}\right)$ after 5 min of rest (ABL 700 series blood gas analyzer, Radiometer, Copenhagen). Measurement was performed native, except few patients with consistent oxygen supplementation during blood gas analysis over all study visits.

\section{COPD-specific health status}

Severity of dyspnea was assessed by modified medical research council (mMRC) scale [20], for which an MID is not available due to its poor evaluative properties to detect changes in dyspnea [21]. COPD Assessment Test (CAT) was performed to measure the impact of COPD symptoms on health status [22] with an estimated MID of 2 points [23].

To assess states of anxiety and depression, the selfadministered Hospital Anxiety and Depression Scale (HADS) was used. The questionnaire is composed of two 7-item sub-scales (HADS-A for anxiety and HADS$\mathrm{D}$ for depression), sub-scores ranging from 0 to 21 with higher scores indicating more severe distress. A score of 0 to 7 is suggested to be non-cases, 8 to 10 as possible cases, and $>10$ as probable cases of clinical anxiety or depression, respectively [24]. A change of 1.5 points is suggested to be the MID [25].

\section{Comorbidities and survival}

Comorbidities were annually assessed by review of the documented medical history, conducting clinical interviews and clinical examinations. To classify comorbidities, the International Classification of Diseases-Tenth Revision [26] was used. The number of comorbidities was calculated by sum up the various diseases.

Last update in April 2019 was used to evaluate patients who died within or after the study period and to assess survival time. Survival time was defined as time from baseline visit to death or April 2019 in patients who stayed alive. In patients who were lost of follow-up, survival time was not calculated.

\section{Exacerbation history}

An acute exacerbation (AE) was defined as an increase in patient's dyspnea, cough and/or sputum with prescription of antibiotics and/or corticosteroids. Severe exacerbation was determined as hospital admission due to AE. Annual acquisition of number of AEs during the preceding year was performed and patients were categorized into infrequent exacerbators $(0-1 \mathrm{AE}$ per year) and frequent exacerbators ( $\geq 2$ AEs per year) [27]. To get the most accurate information on $\mathrm{AE}$, patients reports were compared with documents from the general practitioner, pulmonologist and hospital.

\section{Data analysis and statistics}

All results are shown as mean values (standard deviation (SD)) or median $(25 \% / 75 \%$ quartiles) unless otherwise stated. Statistical analysis was performed with STATA 15.1 (StataCorp, Texas, USA).

Overall differences in PC-PA quadrants and in changing groups were compared by Kruskal-Wallis rank sum test, due to the small sample size in some of the subgroups, and Chi square tests. For continuous variables, non-parametric post-hoc tests were used to compare the sub-groups among each other, $p$-values were Bonferroni corrected. Post-hoc analysis of categorical variables were assessed by Chi square test. For longitudinal data 
analysis, median annual change in each patients' clinical characteristics was calculated.

A two-sided p-value of $<0.05$ was considered to be statistically significant.

\section{Results}

Study participants

Of the 326 patients who agreed to take part, 283 COPD patients (41\% spirometric GOLD stage $1 / 2$, 37\% stage 3,

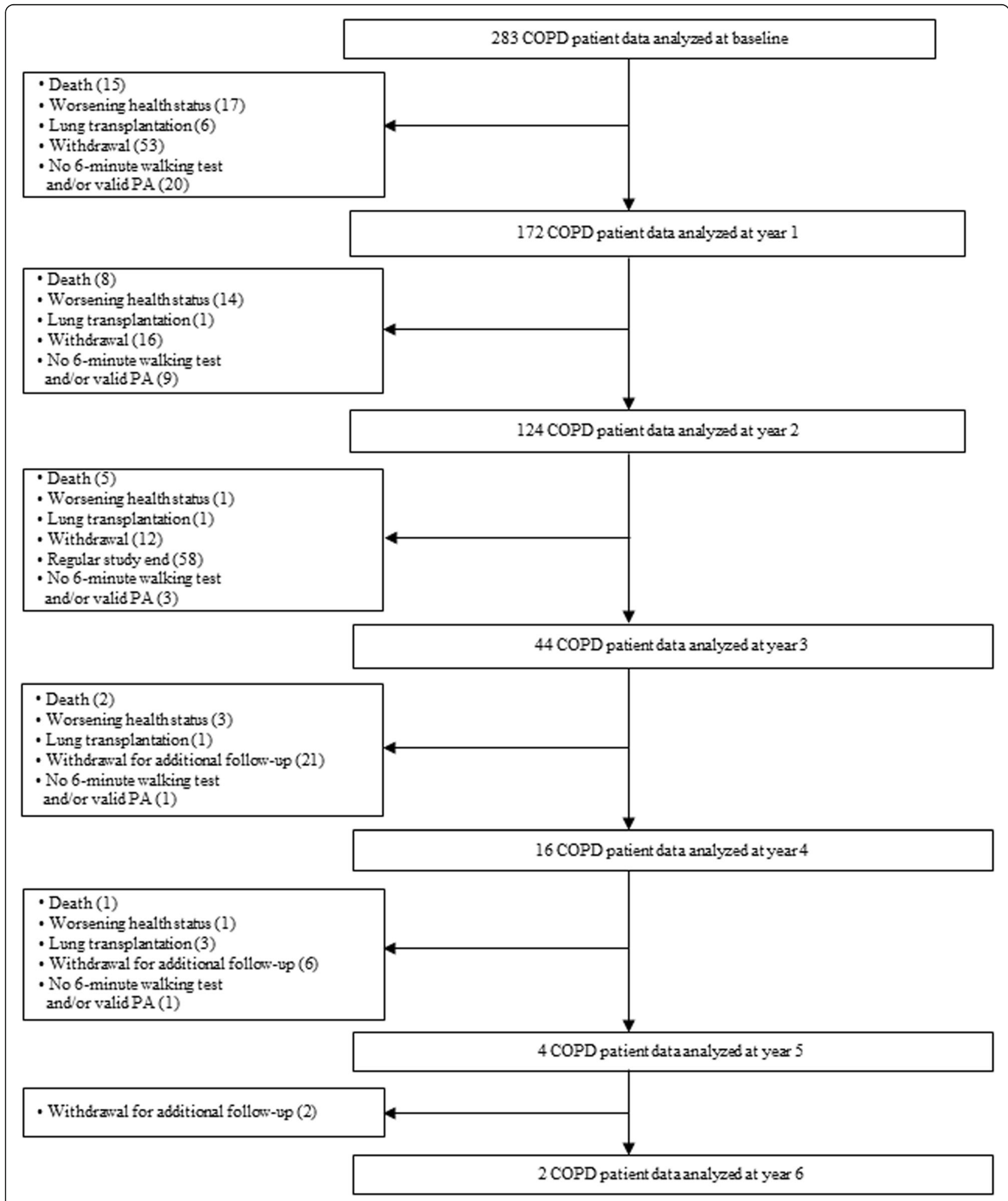

Fig. 1 Study flow 
$23 \%$ stage 4) completed baseline visit and were included in the analysis. Patients were asked to participate for at least three study visits, with some patients extended up to 7 study visits. During follow-up, 172 patients were analysed at year 1, 124 at year 2, 44 at year 3, 16 at year 4,4 at year 5 and 2 at year 6 , respectively (Fig. 1). Reasons for missing follow-up visits were withdrawal, not able to participate anymore due to worsening health status, lung transplantation, and death. Mean $(\mathrm{min} / \mathrm{max})$ follow-up time was 2.4 (0.5/6.8) years with annual measurements (median (quartiles) time between two visits $1.08(1.01 / 1.20))$. Comparison between patients who received follow-up and patients who were lost for or failed follow-up showed no differences in baseline PC and PA. The median (quartiles) age was 63 (58/68) years, 65\% were male and $24 \%$ of the COPD patients were current smokers. Mean (SD) PC was 79.4 (23.1)\% of predicted 6MWD corresponding to 418 (125.7) meter. Median (quartiles) PA was 4421 (2522/6863) steps per day. Detailed patient characteristics are presented in Table 1.

\section{PC-PA quadrants}

At baseline, 30\% (85 patients) were categorized into the "can't do, don't do" quadrant, 29\% (81 patients) into the "can do, don't do" quadrant, 5\% (13 patients) into the "can't do, do do" and 37\% (104 patients) into the "can do, do do" quadrant (Fig. 2).

\section{Differences in clinical characteristics in PC-PA quadrants}

Comparison of the PC-PA quadrants revealed significant overall differences in various baseline values of clinical characteristics, such as lung function, CAT score and number of comorbidities (Table 2). In year 1, the overall significant differences in clinical characteristics in the PC-PA quadrants partly changed compared to baseline (Additional file 1: Table S1). None of the clinical characteristics showed significant and relevant differences between all of the individual quadrants (Table 3). The PCPA quadrants could be characterized as follows: I) "can't do, don't do" quadrant: most severe and symptomatic COPD patients, several comorbidities II) "can do, don't do" quadrant: severe but less symptomatic COPD patients, several comorbidities III) "can't do, do do" quadrant: few patients, severe and symptomatic, less comorbidities IV) "can do, do do" quadrant: mildest and less symptomatic patients, less comorbidities, lowest exacerbation frequency.

Median differences in CAT score between patients with low PC and patients with preserved PC are remarkably above the MID of 2 points, despite lack of statistical significance. Lung function impairment increases from "can do, do do" quadrant to "can do, don't do"/"can't do, do do" to "can't do, don't do" quadrant, with quite similar values between "can't do, do do" and "can do, don't
Table 1 Baseline characteristics

\begin{tabular}{|c|c|}
\hline \multicolumn{2}{|l|}{$N=283$} \\
\hline Age, y & $63(58 / 68)$ \\
\hline Male / Female, N & 184 / 99 \\
\hline $\mathrm{BMI}, \mathrm{kg} / \mathrm{m}^{2}$ & $25.8(22.4 / 28.7)$ \\
\hline Waist / Hip ratio & $0.97(0.91 / 1.03)$ \\
\hline Smoker / Former smoker, N (\%) & $\begin{array}{l}67(24) / 207 \\
(73)\end{array}$ \\
\hline Pack years, $N$ & $40(30 / 60)$ \\
\hline mMRC score & $2(1 / 2)$ \\
\hline CAT score & $15(11 / 20)$ \\
\hline Anxiety score & $4(2 / 8)$ \\
\hline Depression score & $4(2 / 7)$ \\
\hline \multicolumn{2}{|l|}{ GOLD, N (\%) } \\
\hline I & $25(9)$ \\
\hline$\|$ & $92(33)$ \\
\hline III & $103(36)$ \\
\hline IV & $63(22)$ \\
\hline \multicolumn{2}{|l|}{ COPD Risk Group, N (\%) } \\
\hline A & $48(17)$ \\
\hline B & $192(68)$ \\
\hline C & $9(3)$ \\
\hline $\mathrm{D}$ & $34(12)$ \\
\hline $\mathrm{FEV}_{1}, \%$ pred. & $44(31 / 64)$ \\
\hline RV/TLC, \% & $55.6(11.7)$ \\
\hline TLco, ml/mmHg/min & $47(35 / 68)$ \\
\hline $\mathrm{PaO}_{2}, \mathrm{kPa}$ & $9.04(8.21 / 10.13)$ \\
\hline $\mathrm{PaCO}_{2}, \mathrm{kPa}$ & $5.03(4.63 / 5.45)$ \\
\hline $\mathrm{SaO}_{2}, \%$ & $94.7(93.0 / 96.0)$ \\
\hline Number of comorbidities, $\mathrm{N}$ & $3(1 / 4)$ \\
\hline Number of exacerbations in the previous year, $\mathrm{N}$ & $1(0 / 1)$ \\
\hline $\begin{array}{l}\text { Number of severe exacerbations in the previous year, } \\
\mathrm{N}\end{array}$ & $0(0 / 0)$ \\
\hline Frequent exacerbator, N (\%) & $68(24)$ \\
\hline Survival time, days & $\begin{array}{l}2094(1420 / \\
2483)\end{array}$ \\
\hline Retired person, N (\%) & $191(68)$ \\
\hline $6 \mathrm{MWD}, \mathrm{m}$ & $418.3(125.7)$ \\
\hline 6MWD, \% pred. & $79.4(23.1)$ \\
\hline $\mathrm{SpO}_{2}$ after $6 \mathrm{MWT}, \%$ & $90(84 / 95)$ \\
\hline Steps per day, $\mathrm{N}$ & $\begin{array}{l}4421(2522 / \\
6863)\end{array}$ \\
\hline
\end{tabular}

$B M I$ body mass index, $m M R C$ modified medical research council, CAT COPD assessment test, $F E V$, forced expiratory volume in one second, $R V / T L C$ residual volume to total lung capacity ratio, TLCo diffusing capacity of the lung for carbon monoxide, $\mathrm{PaO}_{2}$ partial pressure of oxygen; $\mathrm{PaCO}_{2}$ partial pressure of carbon dioxide; $\mathrm{SaO}_{2}$ oxygen saturation, $6 \mathrm{MWD}$ 6-min walking distance. 


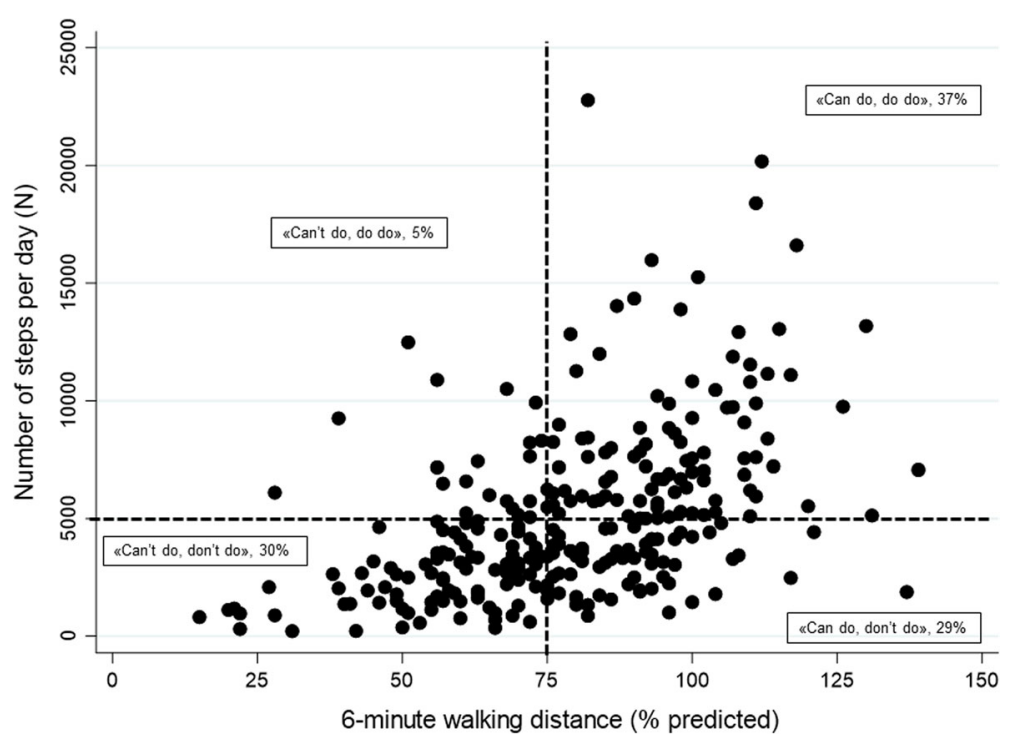

Fig. 2 PC-PA quadrant at baseline. 6-min walking distance ( $x$-axis) is potted against number of steps per day (y-axis)

do" quadrants. The median (95\% CI) difference in 6MWD was above the MID with $35.2(-13.2 / 83.7)$ meters in both groups with low PC, without statistical significance. In the two groups with preserved PC, patients in the "can do, don't do" quadrant showed a relevant but not significant median $(95 \% \mathrm{CI})$ difference in $6 \mathrm{MWD}$ of - 41.7 (-67.8/-15.6). Differences in steps per day were rather small between low PA groups and between preserved PA groups, respectively. (Table 3).

\section{Longitudinal properties of the PC-PA quadrant}

After one year, the percentage of patients in the "can't do, don't do" quadrant declined from 30 to $19 \%$ while the number of patients in the "can do, don't do" quadrant increased from 29 to $44 \%$. The amount of patients in the remaining two quadrants stayed quite stable (3 and $34 \%$, respectively). Of the 172 patients with at least one follow-up visit, 100 (58\%) patients never changed their quadrant affiliation during study period (remainer), while 29 patients (17\%) worsened either PC, PA or both (decliner), 20 patients (11\%) increased their PC, PA or both (improver), and 24 patients (14\%) showed increase and decrease in PC, PA or both (waverer). Follow-up time was significantly longer in the waverer group with median (quartiles) of 3.1 (2.2/4.0) years compared to the remainer $(2.1(1.3 / 2.5)$ years $)$ and decliner (2.0 (1.1/3.1) years) $(p<0.001$ and $p=0.011$, respectively).

Of the patients in the "can't do, don't do" quadrant at baseline, $51 \%$ remained in this quadrant while $24 \%$ were improver and $24 \%$ waverer. In the "can do, don't do" quadrant, $63 \%$ were remainer, $7 \%$ decliner, $15 \%$ improver and waverer each. $40 \%$ of the "can't do, do do" quadrant remained, while $20 \%$ were improver and $40 \%$ waverer. The "can do, do do" quadrant at baseline yield $60 \%$ remainer, $35 \%$ decliner and 5\% waverer.

Median yearly changes in most of the clinical characteristics were comparable among the PC-PA quadrants. The significant greater annual decline in number of steps per day in the "can't do, do do" quadrant compared to the "can do, don't do" quadrant did not show clinical relevance (median (quartiles) difference of $-449(-2728 / 1284)$ steps per day) $(p=0.001)$. (Additional file 1: Table S2).

Differences in clinical characteristics in "changing groups" None of the clinical parameters at baseline yield meaningful differences between all of the four changing groups (Additional file 1: Table S3). Improver showed a significantly higher CAT score (median $(95 \% \mathrm{CI})$ difference of $4.6(1.3 / 7.9)$ ) compared to remainer, and decliner showed a significantly higher RV/TLC (median (95\% CI) difference of $7(3 / 10) \%)$ compared to remainer. 6MWD and number of steps per day was lowest in the improver group and highest in the decliner group. Furthermore, median annual changes in clinical characteristics did not differ relevantly between the changing groups despite a relevant median (quartiles) difference in yearly change in number of steps per day between decliners and improvers of $-1120(-1722 /-557)$ steps $(p<0.001)$. (Table 4$)$.

\section{Discussion}

This analysis applyed a recently introduced concept, taking into account the differences in PC and PA for characterizing COPD patients, in our heterogeneous cohort with longitudinal assessments. Patients with low PC and PA presented the worst health status, followed by patients with low PC but preserved PA and patients with preserved PC but low PA. 
Table 2 Comparison of clinical characteristics between quadrants at baseline

\begin{tabular}{|c|c|c|c|c|c|}
\hline & $\begin{array}{l}\text { "Can't do, don't do" } \\
N=85\end{array}$ & $\begin{array}{l}\text { "Can do, don't do" } \\
N=81\end{array}$ & $\begin{array}{l}\text { "Can't do, do do" } \\
N=13\end{array}$ & $\begin{array}{l}\text { "Can do, do do" } \\
N=104\end{array}$ & $\begin{array}{l}\text { Overall } \\
p \text {-value }\end{array}$ \\
\hline Age, y & $64(60 / 69)$ & $64(58 / 67)$ & $56(53 / 60)^{* \dagger}$ & $64(58 / 68)^{\ddagger}$ & 0.007 \\
\hline Male, N (\%) & $63(74)$ & $51(63)$ & $7(54)$ & $63(61)$ & 0.180 \\
\hline $\mathrm{BMI}, \mathrm{kg} / \mathrm{m}^{2}$ & $24.9(21.1 / 28.1)$ & $26.6(22.8 / 29.4)$ & $24.0(22.6 / 25.8)$ & $26.7(22.6 / 29.2)$ & 0.110 \\
\hline Waist/Hip ratio & $0.98(0.90 / 1.05)$ & $0.98(0.93 / 1.02)$ & $0.93(0.90 / 1.02)$ & $0.96(0.89 / 1.01)$ & 0.250 \\
\hline Smoker, N (\%) & $11(13)$ & $25(31)^{*}$ & $2(15)$ & $29(28)^{*}$ & 0.026 \\
\hline mMRC score & $3(2 / 3)$ & $1(1 / 2)^{*}$ & $2(1 / 3)$ & $1(1 / 2)^{*}+\neq$ & $<0.001$ \\
\hline CAT score & $18(14 / 23)$ & $14(10 / 18)^{*}$ & $19(13 / 22)$ & $13(8 / 19)^{*}$ & $<0.001$ \\
\hline Anxiety score & $5(3 / 8)$ & $3(2 / 6)$ & $7(5 / 9)$ & $4.5(2.0 / 8.0)$ & 0.080 \\
\hline Depression score & $6(4 / 8)$ & $4(2 / 6)^{*}$ & $5(2 / 8)$ & $3.5(1.0 / 6.0)^{*}$ & $<0.001$ \\
\hline GOLD, N (\%) & & & & & $<0.001$ \\
\hline 1 & $2(2)$ & $6(7)$ & $0(0)$ & $17(16)^{*}$ & \\
\hline$\|$ & $11(13)$ & $27(33)^{*}$ & $6(46)^{*}$ & $48(46)^{*}$ & \\
\hline III & $35(41)$ & $36(44)$ & $3(23)$ & $29(28)^{\dagger}$ & \\
\hline IV & $37(44)$ & $12(15)^{*}$ & $4(31)$ & $10(10)^{* \ddagger}$ & \\
\hline COPD Risk Group, N (\%) & & & & & $<0.001$ \\
\hline A & $4(5)$ & $16(20)^{*}$ & $1(8)$ & $27(26)^{*}$ & \\
\hline$B$ & $68(80)$ & $54(67)$ & $10(77)$ & $60(58)^{*}$ & \\
\hline C & $1(1)$ & $0(0)$ & $0(0)$ & $8(8)^{*^{+}}$ & \\
\hline $\mathrm{D}$ & $12(14)$ & $11(14)$ & $2(15)$ & $9(9)$ & \\
\hline $\mathrm{FEV}_{1}, \%$ pred. & $31(25 / 43)$ & $45(34 / 65)^{*}$ & $41(29 / 56)$ & $58(40.5 / 75.0)^{* \dagger}$ & $<0.001$ \\
\hline $\mathrm{RV} / \mathrm{TLC}, \%$ & $63(57 / 68)$ & $55(45 / 65)^{*}$ & $55(46 / 62)$ & $52(43 / 59)^{*}$ & $<0.001$ \\
\hline TLco, \% pred. & $36(28 / 45)$ & $47(36 / 64)^{*}$ & $43(34 / 48)$ & $63(46 / 78)^{*+\neq}$ & $<0.001$ \\
\hline $\mathrm{PaO}_{2}, \mathrm{kPa}$ & $8.6(7.6 / 9.5)$ & $9.0(8.4 / 10.1)$ & $9.3(8.5 / 9.6)$ & $9.6(8.8 / 10.5)^{*}$ & $<0.001$ \\
\hline $\mathrm{PaCO}_{2}, \mathrm{kPa}$ & $5.2(4.7 / 5.7)$ & $5.0(4.5 / 5.3)^{*}$ & $5.0(4.7 / 5.2)$ & $4.9(4.6 / 5.4)$ & 0.047 \\
\hline $\mathrm{SaO}_{2}, \%$ & $93.7(91.2 / 95.3)$ & $94.8(93.3 / 96.0)$ & $94.8(94.5 / 96.0)$ & $95.2(93.7 / 96.5)^{*}$ & 0.007 \\
\hline Number of comorbidities, $\mathrm{N}$ & $3(2 / 5)$ & $3(2 / 5)$ & $2(1 / 2)^{* \dagger}$ & $2(1.0 / 3.5)^{*{ }^{\dagger}}$ & $<0.001$ \\
\hline Exacerbations in the previous year, $\mathrm{N}$ & $1(0 / 2)$ & $0(0 / 1)$ & $1(0 / 2)$ & $0(0 / 1)^{* \neq}$ & $<0.001$ \\
\hline Severe exacerbations in the previous year, $\mathrm{N}$ & $0(0 / 1)$ & $0(0 / 0)^{*}$ & $0(0 / 0)$ & $0(0 / 0)^{*}$ & 0.006 \\
\hline Frequent exacerbator, N (\%) & $28(33)$ & $20(25)$ & $6(46)$ & $14(14)^{* \neq}$ & 0.004 \\
\hline Survival time, days $(N=214)$ & $1550(836 / 2268)^{a}$ & $2115(1599 / 2394)^{b}$ & $2390(1799 / 3019)^{c}$ & $2279(1944 / 2839)^{d_{* \dagger}}$ & $<0.001$ \\
\hline Retired person, N (\%) & $64(76)$ & $56(70)$ & $7(54)$ & $64(62)$ & 0.130 \\
\hline $6 \mathrm{MWD}, \mathrm{m}$ & $300(252 / 349)$ & $450(390 / 510)^{*}$ & $360(300 / 375)^{\dagger}$ & $495(444 / 562)^{* \neq}$ & $<0.001$ \\
\hline $6 \mathrm{MWD}, \%$ pred. & $57(47 / 65)$ & $87(77 / 95)^{*}$ & $61(56 / 65)^{\dagger}$ & $96(95 / 107)^{* \neq}$ & $<0.001$ \\
\hline $\mathrm{SpO}_{2}$ after $6 \mathrm{MWT}, \%$ & $87(81 / 92)$ & $90(85 / 93)^{*}$ & $91(87 / 95)$ & $92(87 / 95)^{*}$ & $<0.001$ \\
\hline Steps per day, N & $2388(1329 / 3357)$ & $3284(2113 / 3864)$ & $6590(6007 / 9258)^{* \dagger}$ & $7553(5876 / 9819)^{* \dagger}$ & $<0.001$ \\
\hline
\end{tabular}

Values are median (25\%/75\% quartiles) unless otherwise stated. * $p<0.05$ vs "can't do, don't do"; ${ }^{\dagger} p<0.05$ vs "can do, don't do"; ${ }^{\ddagger} p<0.005$ vs "can't do, do do". ${ }^{\mathrm{a}} N=69 ;{ }^{\mathrm{b}} \mathrm{N}=62 ;{ }^{\mathrm{c}} \mathrm{N}=8 ;{ }^{\mathrm{d}} \mathrm{N}=75$. BMI body mass index, $m M R C$ modified medical research council, CAT COPD assessment test, $F E V$, forced expiratory volume in one second, $R V / T L C$ residual volume to total lung capacity ratio, $T L C O$ diffusing capacity of the lung for carbon monoxide, $\mathrm{PaO} \mathrm{O}_{2}$ partial pressure of oxygen, $\mathrm{PaCO} \mathrm{O}_{2}$ partial pressure of carbon dioxide, $\mathrm{SaO}_{2}$ oxygen saturation, $6 \mathrm{MWD}$ 6-min walking distance

Preserved PC and PA was found in patients with the mildest disease manifestations. Although $42 \%$ of the patients changed their quadrant affiliation over time, none of the observed clinical characteristics or their annual changes allowed to distinguish between patients who maintained, improved or decreased physical functioning over time.
Several studies demonstrated the deleterious impact of reduced PC and PA on various outcomes in patients with COPD [28-31]. Despite the effort to clarify the relation of physical functioning and progress of COPD, reasons for the divergent evolution between $\mathrm{PC}$ and PA remain unknown. Why the positive effect of 
Table 3 Differences in characteristics between individual quadrants at baseline

\begin{tabular}{|c|c|c|c|c|c|c|}
\hline & $\begin{array}{l}\text { "Can't do, don't do" } \\
\text { vs "Can do, don't do" }\end{array}$ & $\begin{array}{l}\text { "Can't do, don't do" } \\
\text { vs "Can't do, do do" }\end{array}$ & $\begin{array}{l}\text { "Can't do, don't do" } \\
\text { vs "Can do, do do" }\end{array}$ & $\begin{array}{l}\text { "Can do, don't do" } \\
\text { vs "Can't do, do do" }\end{array}$ & $\begin{array}{l}\text { "Can do, don't do" } \\
\text { vs "Can do, do do" }\end{array}$ & $\begin{array}{l}\text { "Can't do, do do" } \\
\text { vs "Can do, do do" }\end{array}$ \\
\hline Age, y & $-1(-3 / 2)$ & $-8(-11 /-4)^{*}$ & $1(-3 / 1)$ & $-7(-10 /-4)^{*}$ & $0(-2 / 2)$ & $7(3 / 10)^{*}$ \\
\hline mMRC score, $\mathrm{N}$ & $-1(-1 /-1)^{*}$ & $0(-1 / 0)$ & $-1(-2 /-1)^{*}$ & $1(0 / 1)$ & $0(-1 / 0)^{*}$ & $-1(-2 / 0)^{*}$ \\
\hline CAT score, $N$ & $-4.3(-6.1 /-2.4)^{*}$ & $-0.14(-4.0 / 3.7)$ & $-4.6(-6.7 /-2.6)^{*}$ & $4.1(0.6 / 7.6)$ & $-0.4(-2.4 / 1.6)$ & $-4.5(-8.9 /-0.1)$ \\
\hline Depression score, $\mathrm{N}$ & $-2(-3 /-1)^{*}$ & $-1(-3 / 2)$ & $-2(-3 /-1)^{*}$ & $1(-1 / 4)$ & $0(-1 / 1)$ & $-1(-4 / 1)$ \\
\hline $\mathrm{FEV}_{1}, \%$ pred. & $13(8 / 18)^{*}$ & $7(-2 / 20)$ & $23(17 / 30)^{*}$ & $-5(-15 / 5)$ & $9(3 / 16)^{*}$ & $15(6 / 25)$ \\
\hline $\mathrm{RV} / \mathrm{TLC}, \%$ & $-7(-10.9 /-4.0)^{*}$ & $-7(-14 / 0)$ & $-11(-14 /-8)^{*}$ & $0(-7 / 7)$ & $-4(-8 / 0)$ & $-4(-11 / 3)$ \\
\hline TLco, \% pred. & $11(6 / 17)^{*}$ & $6(-2 / 15)$ & $25(18 / 31)^{*}$ & $-5(-16 / 4)$ & $12(5 / 18)^{*}$ & $18.5(8 / 28)^{*}$ \\
\hline $\begin{array}{l}\text { Number of } \\
\text { comorbidities, N }\end{array}$ & $-1(-1 / 0)$ & $-2(-2 /-1)^{*}$ & $-1(-2 /-1)^{*}$ & $-1(-2 / 0)^{*}$ & $-1(-1 / 0)^{*}$ & $1(0 / 1)$ \\
\hline $\begin{array}{l}\text { Exacerbations in the } \\
\text { previous year, } \mathrm{N}\end{array}$ & $0(-1 / 0)$ & $0(-1 / 1)$ & $-1(-1 / 0)^{*}$ & $1(0 / 2)$ & $0(0 / 0)$ & $-1(-2 / 0)^{*}$ \\
\hline $\begin{array}{l}\text { Severe exacerbations } \\
\text { in the previous year, } \mathrm{N}\end{array}$ & $0(0 / 0)^{*}$ & $0(0 / 0)$ & $0(0 / 0)^{*}$ & $0(0 / 0)$ & $0(0 / 0)$ & $0(0 / 0)$ \\
\hline $\begin{array}{l}\text { Survival time, days } \\
(N=214)\end{array}$ & $332(49 / 698)$ & $884(328 / 1358)$ & $732(386 / 1075)^{*}$ & $461(-181 / 1069)$ & $303(62 / 568)^{*}$ & $-84(-701 / 467)$ \\
\hline $6 \mathrm{MWD}, \mathrm{m}$ & $169.0(182.8 / 195.2)^{*}$ & $35.2(-13.2 / 83.7)$ & $210.7(185.5 / 236.0)^{*}$ & $\begin{array}{l}-133.8(-184.4 / \\
83.2)^{*}\end{array}$ & $41.7(15.6 / 67.8)$ & $\begin{array}{l}175.5(123.8 / \\
227.2)^{*}\end{array}$ \\
\hline $6 \mathrm{MWD}, \%$ pred. & $32(28 / 36)^{*}$ & $2(-3 / 8)$ & $40(36 / 44)^{*}$ & $-29(-36 /-22)^{*}$ & $7(3 / 12)$ & $37(31 / 44)^{*}$ \\
\hline $\mathrm{SpO}_{2}$ after $6 \mathrm{MWT}, \%$ & $2(0 / 5)^{*}$ & $4(1 / 7)$ & $-4(2 / 7)^{*}$ & $1(-1 / 4)$ & $2(4 / 1)$ & $1(-2 / 3)$ \\
\hline Steps per day, $\mathrm{N}$ & $692(263 / 1108)$ & $4770(3716 / 6145)^{*}$ & $5193(4657 / 5822)^{*}$ & $3990(2916 / 5641)^{*}$ & $4477(3939 / 5130)^{*}$ & $349(-627 / 1508)$ \\
\hline
\end{tabular}

Values are median $(95 \% \mathrm{Cl}) .{ }^{*} p$-value $<0.05 . \mathrm{mMRC}$ modified medical research council, CAT COPD assessment test, FEV forced expiratory volume in one second, $R V / T L C$ residual volume to total lung capacity ratio, TLCo diffusing capacity of the lung for carbon monoxide, $6 M W D$ 6min walking distance, $\mathrm{SaO}_{2}$ oxygen saturation

Table 4 Comparison of median annual change in clinical characteristics between changing groups

\begin{tabular}{|c|c|c|c|c|c|}
\hline Dependent variable & Remainer $N=100$ & Decliner $N=29$ & Improver $N=20$ & Waverer $N=24$ & $P$-value \\
\hline Median annual change BMl, $\mathrm{kg} / \mathrm{m}^{2}$ & $-0.08(-0.75 / 0.66)$ & $-0.03(-1.09 / 0.46)$ & $0.01(-0.93 / 1.02)$ & $0(-0.71 / 0.35)$ & 0.740 \\
\hline Median annual change Waist/Hip ratio & $0.01(-0.03 / 0.04)$ & $0.01(-0.01 / 0.03)$ & $-0.01(-0.03 / 0.02)$ & $0(-0.04 / 0.02)$ & 0.094 \\
\hline Median annual change mMRC score & $0(0 / 1)$ & $0(0 / 1)$ & $0(-1 / 0)$ & $0(0 / 1)$ & 0.210 \\
\hline Median annual change CAT score & $1(-3 / 3)$ & $2(-2 / 4)$ & $-1(-5 / 3)^{\dagger}$ & $1(-2 / 3)^{\ddagger}$ & 0.042 \\
\hline Median annual change Anxiety score & $0(-2 / 1)$ & $0(-1 / 1)$ & $0(-2 / 1)$ & $0(-1 / 2)$ & 0.330 \\
\hline Median annual change Depression score & $0(-2 / 1)$ & $0(-1 / 2)$ & $-1(-2 / 0)^{\dagger}$ & $0.5(-1.0 / 1.5)$ & 0.045 \\
\hline Median annual change $\mathrm{FEV}_{1}, \%$ pred. & $0(-4 / 6)$ & $0(-3 / 5)$ & $3(-4 / 6)$ & $-2(-6 / 1)^{*}$ & 0.046 \\
\hline Median annual change RV/TLC, \% & $0(-5 / 5)$ & $1(-5 / 5)$ & $0(-3.0 / 2.5)$ & $2.5(-2.5 / 6.0)$ & 0.180 \\
\hline Median annual change TLco, $\%$ pred. & $-2(-6.7 / 4.0)$ & $-3(-9 / 2)$ & $0(-6 / 6)$ & $-1.0(-7.0 / 5.0)$ & 0.400 \\
\hline Median annual change $\mathrm{PaO}_{2}, \mathrm{kPa}$ & $0.1(-0.7 / 0.6)$ & $-0.21(-0.69 / 0.60)$ & $-0.20(-0.82 / 0.56)$ & $0.08(-0.82 / 0.75)$ & 0.840 \\
\hline Median annual change $\mathrm{PaCO}_{2}, \mathrm{kPa}$ & $0(-0.31 / 0.23)$ & $0.01(-0.27 / 0.20)$ & $-0.10(-0.29 / 0.14)$ & $0.02(-0.17 / 0.42)$ & 0.450 \\
\hline Median annual change $\mathrm{SaO}_{2}, \%$ & $0(-1.1 / 1.2)$ & $0.1(-1.5 / 1.0)$ & $-0.2(-1.5 / 1.0)$ & $0(-1 / 1)$ & 0.860 \\
\hline Median annual change Number of comorbidities & $0(0 / 0)$ & $0(0 / 1)$ & $0(0 / 1)$ & $0(0 / 0)$ & 0.100 \\
\hline $\begin{array}{l}\text { Median annual change Exacerbations in } \\
\text { the previous year, } N\end{array}$ & $0(-1 / 0)$ & $0(-1 / 1)$ & $0(-0.5 / 0.0)$ & $0(-1 / 1)$ & 0.850 \\
\hline $\begin{array}{l}\text { Median annual change Severe exacerbations in the } \\
\text { previous year, } N\end{array}$ & $0(0 / 0)$ & $0(0 / 0)$ & $0(0 / 0)$ & $0(0 / 0)$ & 0.810 \\
\hline Median annual change 6MWD, $\mathrm{m}$ & $0(-30 / 30)$ & $-25(-60.0 / 28.7)$ & $11(-18 / 57.5)^{\dagger}$ & $0(-75 / 35)$ & 0.019 \\
\hline Median annual change 6MWD, \% pred. & $1.5(-3.0 / 10.0)$ & $0(-11 / 7)$ & $9.5(-2 / 20)$ & $1(-14 / 14)^{\ddagger}$ & 0.005 \\
\hline Median annual change $\mathrm{SpO}_{2}$ after $6 \mathrm{MWT}, \%$ & $0(-3 / 3)$ & $-1(-3 / 2)$ & $0(-3 / 2)$ & $-1(-5 / 4)$ & 0.540 \\
\hline Median annual change Steps per day, N & $-298(-1418 / 566)$ & $-1202(-2926 /-348)^{*}$ & $-192(-1393 / 1809)^{\dagger}$ & $-761(-1870 / 665)$ & $<0.001$ \\
\hline
\end{tabular}


enhancements in PC, e.g. with pulmonary rehabilitations, cannot always be transferred into enhanced PA is a matter of current debate and research [32]. Furthermore, it remains to be defined if PA modifying interventions, such as PA counselling, also enhances PC for long term. A previous study by our team revealed that the significant decrease in daily PA over time is not accompanied by a decrease in PC [6]. Consistent with these findings, Koolen et al. [10] developed a new concept in which PC and PA were divided into decreased and preserved. This PC-PA quadrant should enable the identification of physical functioning sub-groups with different clinical characteristics and might be useful in optimizing personalized medicine in COPD patients. Following the call to prove the new PC-PA quadrant concept, we applied the concept to our COPD cohort and investigated if the PC-PA quadrant is applicable for dynamic changes, assessed by longitudinal observations. Comparable to Koolen and colleagues [10], patients in the "can't do, don't do" quadrant showed the highest disease burden and patients in the "can do, do do" quadrant the mildest COPD. However, none of the assessed clinical characteristics allowed to distinguish between all of the individual quadrants. Several of the differentiating characteristics found by Koolen et al. [10], such as BMI and sex, could not be confirmed by our study. Moreover, some of the distinguishing characteristics found to be significant in the baseline assessment were not maintained significant in the following year. The largest mismatch was found in the "can do, don't do" patients. Koolen et al. [10] reported the smallest prevalence in these patients and described them as "lazy", with the highest BMI and low exacerbation history. Our data suggested that these patients show a comparable severity of COPD with the "can't do, do do" patients, but with slightly lower symptoms and a higher PC. We thus hypothesize that the already severe respiratory impairment did not translate into a low PC yet, but will lead to an impairment in $\mathrm{PC}$ with a delay in time. This finding could also deliver an explanation why the annual decrease in PA is not accompanied by a decrease in PC [6], leading to the assumption that $\mathrm{PC}$ may decrease with delay while PA impairment goes in line with disease worsening. To address this, longitudinal studies are needed in which early disease stages are monitored and the onset of PA impairment will be compared with the onset of PC impairment. Furthermore, this raises the question if regular assessment of PA in clinical practice would be more sensitive to detect progressive deterioration of COPD compared to the commonly used PC. The PC-PA quadrant concept was not able to project the dynamic course of the disease. Almost half of the patients changed their PC-PA quadrant over time but changes in quadrant affiliation were not connected to clinical characteristics or their annual changes. We therefore assume that detailed characterization of the four PC-PA quadrants would not be adequate. However, further studies are needed to confirm whether patients in the "can do, don't do" quadrant show severe disease burden and if these patients would be more responsive for PA enhancement after pulmonary rehabilitations.

The current study has some limitations. Patients with pulmonary rehabilitation within 3 months prior to the baseline evaluation were not included at this time point. However, we cannot exclude that a small number of severe patients underwent pulmonary rehabilitation during the study period, potentially increased the group of waverers. Furthermore, the number of patients in the "can't do, do do" quadrant is quite small but seems to represent the real-world distribution of COPD patients.

\section{Conclusion}

In conclusion, we found no clinical characteristics to distinguish significantly and clinically meaningful between the PC-PA quadrants. Furthermore, the PC-PA quadrant concept seems not to be able to reflect disease process in COPD patients with a follow-up up to six years. However, the already low PA and preserved PC in the "can do, don't do" quadrant raises the question if regularly assessment of PA in clinical practice would be more sensitive to detect progressive deterioration of COPD compared to the commonly used PC.

\section{Supplementary information}

Supplementary information accompanies this paper at https://doi.org/10. 1186/s12931-020-1290-9.

Additional file 1: Table S1. Comparison of clinical characteristics between quadrants at year 1. Table S2. Comparison of change in clinical characteristics between quadrants. Table S3. Comparison of clinical characteristics at baseline between changing groups.

\section{Abbreviations}

6MWD: 6-min walking distance; 6MWT: 6-min walking test; AE: Acute exacerbation; ATS: American thoracic society; BMI: Body mass index; CAT: COPD Assessment Test; Cl: Confidence interval; COPD: Chronic obstructive pulmonary disease; $\mathrm{FEV}_{1}$ : Forced expiratory volume in $1 \mathrm{~s}$; FVC: Forced vital capacity; GOLD: Global initiative for chronic obstructive lung disease; HADS: Hospital Anxiety and Depression Scale; MID: Minimal important difference; mMRC: Modified medical research council; PA: Physical activity; $\mathrm{PaCO}$ : Partial pressure of carbon dioxide; $\mathrm{PaO} 2$ : Partial pressure of oxygen; PC: Physical capacity; SaO2: Oxygen saturation; TOPDOCS: The obstructive pulmonary disease outcomes cohort of Switzerland

\section{Authors' contributions}

Design of the study: NAS, MK, CFC, acquisition of data: NAS, MK, RT, JDL, SI, $\mathrm{MF}, \mathrm{MB}, \mathrm{TB}, \mathrm{CFC}$, data analysis and interpretation: NAS, MK, CFC, manuscript draft and revision for intellectual content and approved the final version: NAS, MK, RT, JDL, SI, MF, MB, TB, CFC. All authors read and approved the final Manuscript.

\section{Funding}

This study was supported by Lunge Zurich, Lung league of both Basel, Gottfried and Julia Bangerter-Rhyner foundation, Freiwillige Akademische 
Gesellschaft Basel, Lung league of Canton Thurgau, Lung league of Canton St. Gallen, Lung league of Canton Aargau and Lung league of Canton Glarus.

\section{Availability of data and materials}

The datasets used and analysed during the current study are available from the corresponding author on reasonable request.

\section{Ethics approval and consent to participate}

The study was conducted in accordance with the declaration of Helsinki and all subjects gave written informed consent to participate. The Ethics Committee of the Canton of Zurich approved the study (EK-ZH-NR: 1734 and 2011-0106) and the study is registered at www.ClinicalTrials.gov, NCT01527773.

\section{Consent for publication}

Not applicable.

\section{Competing interests}

The authors declare that they have no competing interests.

\section{Author details}

${ }^{1}$ Pulmonary Division, University Hospital Zurich, Raemistrasse 100, 8091 Zurich, Switzerland. ${ }^{2}$ Pulmonary Division, Cantonal Hospital of Glarus, Glarus, Switzerland. ${ }^{3}$ Pulmonary Division, Cantonal Hospital of St. Gallen, St. Gallen, Switzerland. ${ }^{4}$ Pulmonary Division, Clinic Barmelweid, Erlinsbach, Switzerland. ${ }^{5}$ Pulmonary Division, Cantonal Hospital of Aarau, Aarau, Switzerland. ${ }^{6}$ University Department of Medicine, Cantonal Hospital Baselland and University of Basel, Basel, Switzerland. ${ }^{7}$ Pulmonary Division, Cantonal Hospital of Münsterlingen, Münsterlingen, Switzerland. ${ }^{8}$ Zurich Centre for Integrative Human Physiology, University of Zurich, Zurich, Switzerland.

Received: 12 November 2019 Accepted: 8 January 2020

Published online: 20 January 2020

\section{References}

1. Watz H, Waschki B, Meyer T, Magnussen H. Physical activity in patients with COPD. Eur Respir J. 2009;33(2):262-72

2. Arne M, Janson C, Janson S, Boman G, Lindqvist U, Berne C, et al. Physical activity and quality of life in subjects with chronic disease: chronic obstructive pulmonary disease compared with rheumatoid arthritis and diabetes mellitus. Scand J Prim Health Care. 2009;27(3):141-7.

3. Waschki B, Kirsten A, Holz O, Muller KC, Meyer T, Watz H, et al. Physical activity is the strongest predictor of all-cause mortality in patients with COPD: a prospective cohort study. Chest. 2011;140(2):331-42.

4. Puhan MA, Siebeling L, Zoller M, Muggensturm P, ter Riet G. Simple functional performance tests and mortality in COPD. Eur Respir J. 2013;42(4): 956-63

5. Caspersen CJ, Powell KE, Christenson GM. Physical activity, exercise, and physical fitness: definitions and distinctions for health-related research. Public Health Rep. 1985;100(2):126-31.

6. Sievi NA, Brack T, Brutsche MH, Frey M, Irani S, Leuppi JD, et al. Physical activity declines in COPD while exercise capacity remains stable: a longitudinal study over 5 years. Respir Med. 2018;141:1-6.

7. McCarthy B, Casey D, Devane D, Murphy K, Murphy E, Lacasse Y. Pulmonary rehabilitation for chronic obstructive pulmonary disease. Cochrane Database Syst Rev. 2015;(2):Cd003793. https://doi.org/10.1002/14651858.CD003793. pub3.

8. Spruit MA, Pitta F, McAuley E, ZuWallack RL, Nici L. Pulmonary rehabilitation and physical activity in patients with chronic obstructive pulmonary disease. Am J Respir Crit Care Med. 2015;192(8):924-33.

9. Mantoani LC, Rubio N, McKinstry B, MacNee W, Rabinovich RA. Interventions to modify physical activity in patients with COPD: a systematic review. Eur Respir J. 2016;48(1):69-81.

10. Koolen EH, van Hees HW, van Lummel RC, Dekhuijzen R, Djamin RS, Spruit MA, et al. "Can do" versus "do do": A Novel Concept to Better Understand Physical Functioning in Patients with Chronic Obstructive Pulmonary Disease. J Clin Med. 2019:8(3):340

11. Rabe KF, Hurd S, Anzueto A, Barnes PJ, Buist SA, Calverley P, et al. Global strategy for the diagnosis, management, and prevention of chronic obstructive pulmonary disease - GOLD executive summary. Am J Respir Crit Care Med. 2007;176(6):532-55.
12. Brooks D, Solway S, Gibbons WJ. ATS statement on six-minute walk test. AmJRespirCrit Care Med. 2003:167(9):1287.

13. Enright $\mathrm{PL}$, Sherrill $\mathrm{DL}$. Reference equations for the six-minute walk in healthy adults. Am J Respir Crit Care Med. 1998;158(5 Pt 1):1384-7.

14. Holland AE, Hill CJ, Rasekaba T, Lee A, Naughton MT, McDonald CF. Updating the minimal important difference for six-minute walk distance in patients with chronic obstructive pulmonary disease. Arch Phys Med Rehabil. 2010;91(2):221-5.

15. Van Remoortel H, Raste Y, Louvaris Z, Giavedoni S, Burtin C, Langer D, et al. Validity of six activity monitors in chronic obstructive pulmonary disease: a comparison with indirect calorimetry. PLoS One. 2012;7(6):e39198.

16. Demeyer H, Burtin C, Hornikx M, Camillo CA, Van Remoortel H, Langer D, et al. The minimal important difference in physical activity in patients with COPD. PLoS One. 2016;11(4):e0154587.

17. Miller MR, Hankinson J, Brusasco V, Burgos F, Casaburi R, Coates A, et al. Standardisation of spirometry. Eur Respir J. 2005;26(2):319-38.

18. Macintyre N, Crapo RO, Viegi G, Johnson DC, van der Grinten CP, Brusasco $V$, et al. Standardisation of the single-breath determination of carbon monoxide uptake in the lung. Eur Respir J. 2005;26(4):720-35.

19. Global Initiative for Chronic Obstructive Lung Disease: Global Strategy for the Diagnosis, Management, and Prevention of Chronic Obstructive Disease. https://goldcopd.org/global-strategy-diagnosis-management-preventioncopd-2016. Accessed 12 Nov 2019. 2016.

20. Mahler DA, Wells CK. Evaluation of clinical methods for rating dyspnea. Chest. 1988;93(3):580-6.

21. Mahler DA, Weinberg DH, Wells CK, Feinstein AR. The measurement of dyspnea. Contents, interobserver agreement, and physiologic correlates of two new clinical indexes. Chest. 1984;85(6):751-8.

22. Jones PW, Harding G, Berry P, Wiklund I, Chen WH, Kline LN. Development and first validation of the COPD assessment test. Eur Respir J. 2009;34(3): 648-54.

23. Kon SS, Canavan JL, Jones SE, Nolan CM, Clark AL, Dickson MJ, et al. Minimum clinically important difference for the COPD assessment test: a prospective analysis. Lancet Respir Med. 2014;2(3):195-203.

24. Zigmond AS, Snaith RP. The hospital anxiety and depression scale. Acta Psychiatr Scand. 1983;67(6):361-70.

25. Puhan MA, Frey M, Buchi S, Schunemann HJ. The minimal important difference of the hospital anxiety and depression scale in patients with chronic obstructive pulmonary disease. Health Qual Life Outcomes. 2008;6:46.

26. WHO. International Classification of Diseases (ICD). 2013. http://www.who. int/classifications/icd/en. Accessed 12 Nov 20192013 [.

27. Hurst JR, Vestbo J, Anzueto A, Locantore N, Mullerova H, Tal-Singer R, et al. Susceptibility to exacerbation in chronic obstructive pulmonary disease. NEnglJMed. 2010;363(12):1128-38.

28. Esteban C, Quintana JM, Aburto M, Moraza J, Egurrola M, Perez-Izquierdo J, et al. Impact of changes in physical activity on health-related quality of life among patients with COPD. Eur Respir J. 2010;36(2):292-300.

29. Vaes AW, Garcia-Aymerich J, Marott JL, Benet M, Groenen MT, Schnohr P, et al. Changes in physical activity and all-cause mortality in COPD. Eur Respir J. 2014:44(5):1199-209.

30. Esteban C, Arostegui I, Aburto M, Moraza J, Quintana JM, Aizpiri S, et al. Influence of changes in physical activity on frequency of hospitalization in chronic obstructive pulmonary disease. Respirology. 2014;19(3):330-8.

31. Singh SJ, Puhan MA, Andrianopoulos V, Hernandes NA, Mitchell KE, Hill CJ, et al. An official systematic review of the European Respiratory Society/ American Thoracic Society: measurement properties of field walking tests in chronic respiratory disease. Eur Respir J. 2014:44(6):1447-78.

32. Spruit MA, Singh SJ, Garvey C, ZuWallack R, Nici L, Rochester C, et al. An official American Thoracic Society/European Respiratory Society statement: key concepts and advances in pulmonary rehabilitation. Am J Respir Crit Care Med. 2013;188(8):e13-64.

\section{Publisher's Note}

Springer Nature remains neutral with regard to jurisdictional claims in published maps and institutional affiliations. 